\title{
Erratum to: Biomass-Cover Relationship for Eelgrass Meadows
}

\author{
Jacob Carstensen $^{1}$ • Dorte Krause-Jensen ${ }^{2}$ Thorsten J. S. Balsby ${ }^{2}$
}

Published online: 26 February 2016

(C) Coastal and Estuarine Research Federation 2016

Erratum to: Estuaries and Coasts (2016) 39:440-450

DOI 10.1007/s12237-015-9995-6

In the original article there is an error is Eq. 1. The correct equation is as follows:

$B(C, Z)=B_{\max }(Z) \cdot\left(1-\exp \left(-\frac{C(Z)}{k_{C}}\right)\right)$

The online version of the original article can be found at /http:dx.doi.org/ 10.1007/s12237-015-9995-6.

$\triangle$ Jacob Carstensen jac@dmu.dk

1 Department of Bioscience, Aarhus University, Frederiksborgvej 399, DK-4000 Roskilde, Denmark

2 Department of Bioscience, Aarhus University, Vejlsøvej 25, DK-8600 Silkeborg, Denmark 